\title{
Flexible milimeter-wave microstrip patch antenna array for wearable RF energy harvesting applications
}

\author{
Mohd Saiful Riza Bashri ${ }^{1}$, Noor Amalina Ramli ${ }^{2}$ \\ ${ }^{1}$ Department of Science in Engineering, Kulliyyah of Engineering, International Islamic University Malaysia, Malaysia \\ ${ }^{2}$ Department of Electrical and Computer Engineering, Kulliyyah of Engineering, \\ International Islamic University Malaysia, Malaysia
}

\begin{tabular}{l} 
Article Info \\
\hline Article history: \\
Received Sep 11, 2020 \\
Revised Sep 22, 2020 \\
Accepted Oct 14, 2020 \\
\hline
\end{tabular}

\section{Keywords:}

Flexible antenna

Microstrip antenna

RF energy harvester

\begin{abstract}
In this paper, a series-fed milimeter-wave microstrip patch antenna array operating at $28 \mathrm{GHz}$ is presented for wearable radio-frequency (RF) energy harvesting applications. The antenna array is made of $4 \times 4$ rectangular microstrip elements on a polyethylene terephthalate (PET) substrate to provide conformability when directly attached on human body parts. A 4-way Wilkinson power divider is connected to the array for RF power combining. The overall size of the antenna is $47 \times 28 \times 0.25 \mathrm{~mm}$. The halfpower beamwidth (HPBW) of the antenna array can be increased up to $151.9^{\circ}$ via structural deformation making it suitable for energy harvesting applications. The performance of the antenna array is investigated in terms of impedance matching, gain and radiation pattern. The average simulated specific absorption rate (SAR) of the antenna is $0.52 \mathrm{~W} / \mathrm{kg}$ which is well below the safety limit of $1.6 \mathrm{~W} / \mathrm{kg}$ averaged over $1 \mathrm{~g}$ of tissue for $100 \mathrm{~mW}$ of input power.
\end{abstract}

This is an open access article under the CC BY-SA license.

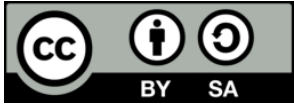

Corresponding Author:

Mohd. Saiful Riza Bashri

Department of Science in Engineering, Kulliyyah of Engineering

International Islamic University Malaysia

Jalan Gombak, 53000 Kuala Lumpur, Malaysia

Email: mohdsaifulriza@iium.edu.my

\section{INTRODUCTION}

In the next few decades, Internet of Things (IoT) and wireless sensor networks (WSN) will become ubiquitous which will contribute to a significant increase in electronic devices worldwide [1-3]. These devices are designed to assist human in various aspects such as health and environment monitoring, diseases detection, communication and industrial process monitoring and control [4, 5]. To operate remotely, IoT devices are expected to be powered up by batteries. As a result, periodic placement of batteries are needed to ensure continuous operation of the devices. In addition, some of them might simply be replaced with a new one altogether. Over time, the accumulation of this electronics waste will become severe which would eventually lead to pollution. It is reported in [1] that there are about 50 million tons of electronic waste every year. As such, to achieve sustainable development in the long run, renewable energy resources such as radio frequency (RF) energy, solar energy, wind energy and thermal energy are required. One of the interesting options is by harvesting RF energy from ambient milimeter-wave signals that are expected to surround us due to future implementation of $5 \mathrm{G}$ standard [6-8]. It is also foreseen that future wireless communication will utilize the higher frequency range compared to the existing networks which currently rely on sub-6 GHz frequency band. 
There are numerous research that have been carried out to develop an efficient RF energy harvester to date [9-32]. However, most of the works reported were conducted for current wireless networks such as GSM900, GSM1800 and Wi-Fi. To anticipate the implementation of 5G technology where more spectrum bands will be used particularly in milimeter wave range, a novel RF energy harvester is required to improve the efficiency, size and cost of the current devices. However, there are several fundamental challenges that need to be addressed in order to harvest RF signal at milimeter-wave frequencies.

In RF energy harvester systems, there are several key components mainly antenna, matching network, rectifying circuit and low pass filter. For harvesting ambient RF energy, the input RF signal is transmitted from the transmitters fat the base stations in the vicinity of the harvesting device. Due to the very low power density of the transmitted signals, an efficient RF harvesting device is needed. One of the methods to improve the efficiency of the rectenna and to increase the received power is by utilizing high gain and wide half-power beamwidth (HPBW) receiving antennas. Moreover, the need for flexible RF energy harvesters that can be comfortably worn and conformal to human body is vital to support the rapid development of wearable devices for various applications such as remote health monitoring, patient tracking and so on.

In this paper, a flexible microstrip antenna array with high gain characteristic operating at $28 \mathrm{GHz}$ is proposed for wearable RF energy harvesting applications. First, we present the design methodology for the microstrip antenna and the 4 -way power divider in section 2 . To improve the gain of the antenna, a $4 \times 4$ array arrangement is employed in this design. The antenna elements are fed at the radiating edge of the antenna. The simulated operating frequency of the antenna is from $27.5 \mathrm{GHz}$ to $28.4 \mathrm{GHz}$. A total of $900 \mathrm{MHz}$ of impedance bandwidth will be sufficient for the antenna to harvest RF energy from the future implementation of $5 \mathrm{G}$ technology which will utilise the $28 \mathrm{GHz}$ frequency band as part of the milimeter wave frequency bands [33]. Next, simulations have been carried out to investigate the performance of the flexible antenna array by deforming it based on various curvatures. In section 3, the results of the simulations are presented and discussed in detail. The numerical simulation results demonstrate that the antenna is suitable to be implemented as wearable RF energy harvesting device. Finally, conclusions are drawn in section 4.

\section{ANTENNA DESIGN AND SIMULATIONS}

The design of the proposed microstrip antenna array integrated with a 4-way Wilkinson power divider is carried out using a commercial electromagnetic wave solver, CST Microwave Studio. First, the $4 \times 4$ antenna array is optimized to operate at $28 \mathrm{GHz}$ through parametric optimization based on the analytical calculation of the initial antenna dimension. Afterwards, a 4-way Wilkinson power divider is developed to be connected to the antenna array for power combining. The device is then deformed in several bending configurations to evaluate its effects on the antenna performance mainly its impedance matching, gain and radiation pattern. The use of $4 \times 4$ antenna array instead of just one single antenna is to increase the antenna gain even when the antenna is in bending configuration.

\subsection{Microstrip antenna configuration}

The initial dimension of the rectangular microstrip patch was calculated analytically by using the widely known closed-form equations described in [34]. The operating frequency of the antenna is defined at $28 \mathrm{GHz}$ to exploit the implementation of $5 \mathrm{G}$ technologies in the future of which the ambient RF energy can be harvested using the antenna. To provide flexibility to the antenna structure, PET material was selected as the substrate. The dielectric constant, $\varepsilon_{r}$ and the loss tangent, $\tan \delta$ of the substrate are 2.1 and 0.03 respectively [35]. The thickness of the substrate is $0.25 \mathrm{~mm}$. An array of $4 \times 4$ elements was chosen to increase the gain of the antenna without having to significantly increase the antenna footprint. The antennas were fed in series at the radiating edges to simplify the overall structure of the array. The radiating element is made up of silver with thickness of $250 \mathrm{~nm}$. The final configuration of the rectangular microstrip antenna array is illustrated in Figure 1 where the antenna parameters are given in Table 1.

\subsection{4-way Wilkinson power divider}

The antenna array designed previously has four separate ports where each separate port is connected to 4 series-fed antenna arrays. As such, to combine all the received power captured by the arrays, a power divider/combiner is required. To achieve this target, a Wilkinson power divider is proposed where it can function as a lossless network when its output ports are matched [36]. The typical configuration of an equalsplit Wilkinson power divider is shown in Figure 2(a). The characteristic impedance of the Wilkinson power divider, $Z_{0}$ is set to $50 \Omega$ to match with the impedance of the antenna port. The power divider is designed in microstrip form to provide seamless power transmission between the antenna array and the proposed power divider. The substrate used in this design is similar to that of the antenna array. The distance between the 
output ports is also set to match the separation distance in the designed array. Since the length of a quarterwave arm in a typical design of Wilkinson power divider is only $2 \mathrm{~mm}$ at $28 \mathrm{GHz}$, it is very difficult to incorporate the required bends due to its limited length. As such, a $3 \lambda / 4$ branch which corresponds to $6 \mathrm{~mm}$ is utilised instead of the quarter-wave transmission line. Moreover, to reduce the reflection of the propagating electromagnetic (EM) signal at the $90^{\circ}$ bends in the design, mitering technique has been applied [37]. The optimized design of the 4-way Wilkinson power divider is shown in Figure 2(b). The values of the parameters of the structure is given in Table 2. Finally, the antenna array and the power divider are integrated as shown in Figure 3.

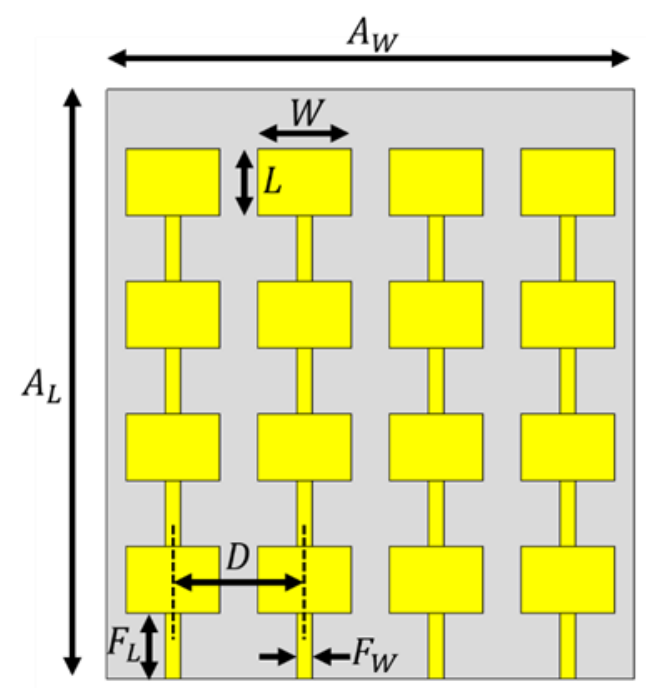

Figure 1. Configuration of the $4 \times 4$ microstrip patch antenna

Table 1. Geometrical parameter of the antenna

\begin{tabular}{ccc}
\hline Antenna Parameter & Symbol & Values $(\mathrm{mm})$ \\
\hline Antenna length & $L$ & 3.47 \\
Antenna width & $W$ & 5 \\
Thickness of the substrate & $T_{S}$ & 0.25 \\
Antenna separation distance & $D$ & 7 \\
Feedline length & $F_{L}$ & 3.47 \\
Feedline width & $F_{W}$ & 0.8 \\
Array length & $A_{L}$ & 32 \\
Array width & $A_{W}$ & 28 \\
\hline
\end{tabular}

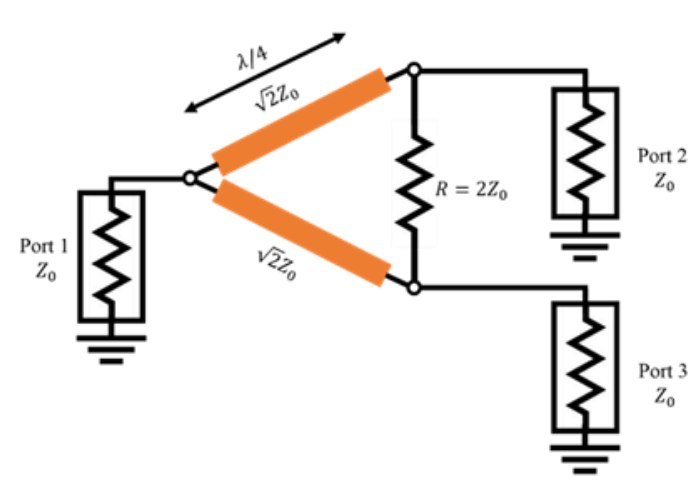

(a)

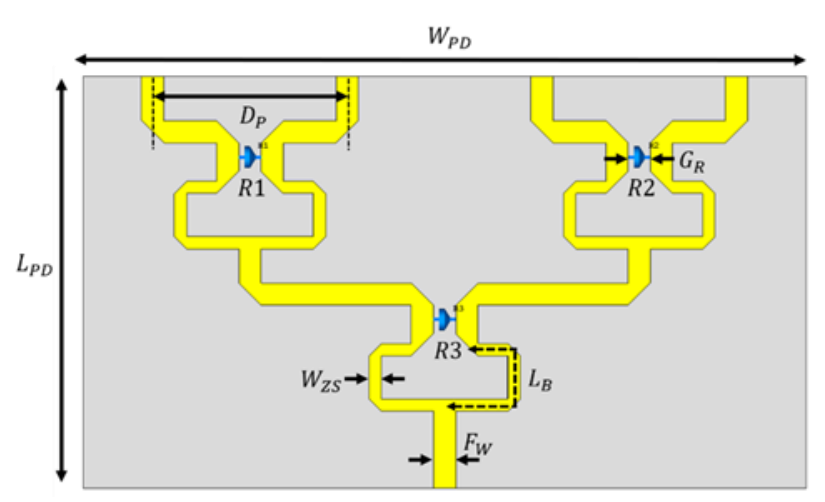

(b)

Figure 2. Wilkinson power divider (a) an equal-split Wilkinson power divider, (b) configuration of the proposed 4-way Wilkinson power divider 
Table 2. Geometrical Parameter of the 4-way Wilkinson Power Divider

\begin{tabular}{ccc}
\hline Parameter & Symbol & Values \\
\hline Wilkinson power divider length & $L_{P D}$ & $15 \mathrm{~mm}$ \\
Wilkinson power divider width & $W_{P D}$ & $28 \mathrm{~mm}$ \\
Port separation distance & $D_{P}$ & $7 \mathrm{~mm}$ \\
Feedline width for $50 \Omega$ transmission line & $F_{W}$ & $0.8 \mathrm{~mm}$ \\
Feedline width for 70.71 $\Omega$ transmission line & $W_{Z S}$ & $0.45 \mathrm{~mm}$ \\
$3 \lambda / 4$ branch length & $L_{B}$ & $6 \mathrm{~mm}$ \\
Branches gap & $G_{R}$ & $0.8 \mathrm{~mm}$ \\
Resistor 1 & $R 1$ & $100 \Omega$ \\
Resistor 2 & $R 2$ & $100 \Omega$ \\
Resistor 3 & $R 3$ & $100 \Omega$ \\
\hline
\end{tabular}

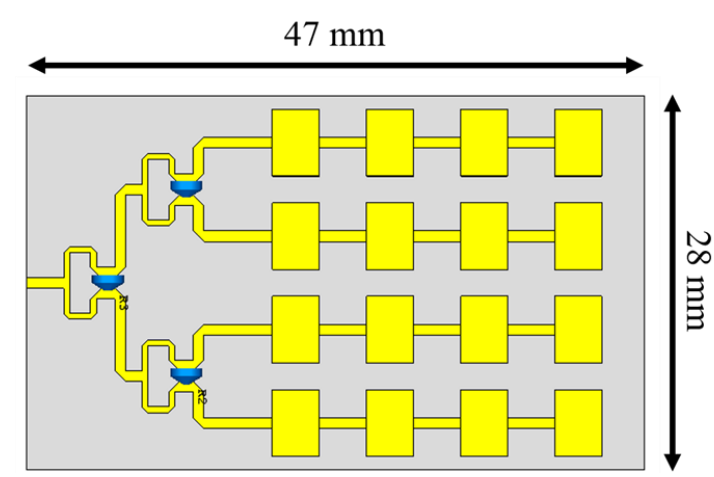

Figure 3. Microstrip antenna array integrated with 4-way Wilkinson power divider

\subsection{Simulation model for antenna array structural deformation}

Since the proposed wearable antenna array is aimed for harvesting RF energy by placing the device on the body, it will be subject to various structural deformations depending on the human body curvature. Therefore, the antenna was first evaluated by bending it according to several bending radius, $R_{b}$ values mainly $10 \mathrm{~mm}, 20 \mathrm{~mm}, 30 \mathrm{~mm}$ and $40 \mathrm{~mm}$ where these values were chosen based on the reasonable representations of a typical human hand. The $S_{11}$, gain and radiation patterns of the antenna were evaluated. Figure 4 shows the diagram of the antennas in the simulations according to the bending radius values.

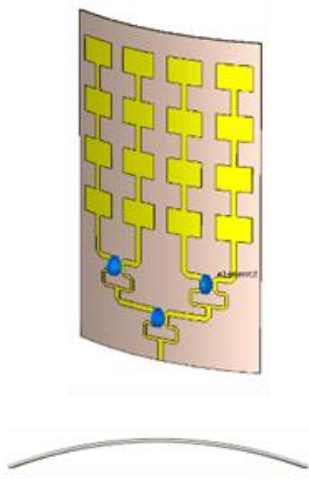

$R b=40 \mathrm{~mm}$

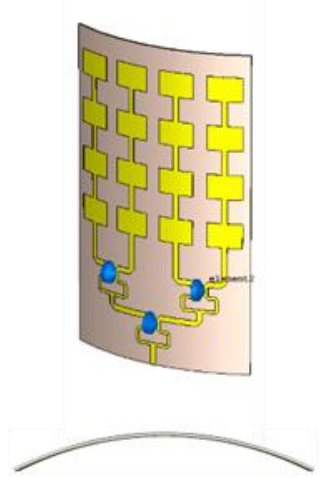

$R b=30 \mathrm{~mm}$

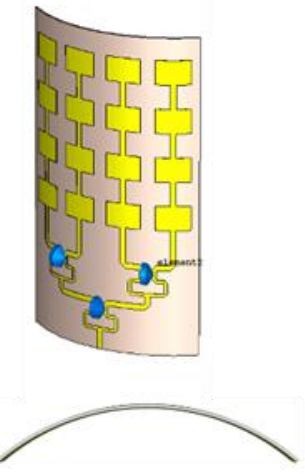

$R b=20 \mathrm{~mm}$

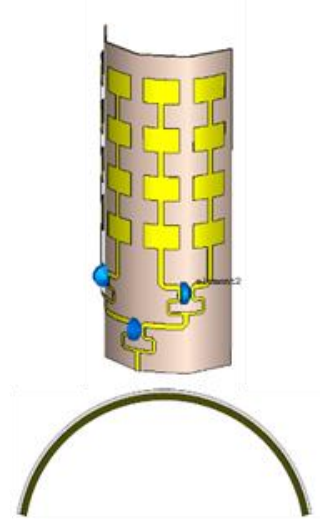

$R b=10 \mathrm{~mm}$

Figure 4. Bending configurations of the antenna with radius of curvatures of $40 \mathrm{~mm}, 30 \mathrm{~mm}, 20 \mathrm{~mm}$ and $10 \mathrm{~mm}$

\section{RESULTS AND ANALYSIS}

The results of the simulations are divided into two parts based on the simulation environments described in the previous section. The first part presents the results for the planar configuration while the second part discusses the antenna performance due to structural deformations. 


\subsection{Performance of antenna in planar configuration}

The simulated $S_{11}$ of the antenna array in planar configuration is shown in Figure 5. It can be seen that impedance matching of the antenna is well below $-10 \mathrm{~dB}$ at $28 \mathrm{GHz}$ which is $-25 \mathrm{~dB}$. A good separation distance between the antenna elements is achieved indicated by mutual coupling of less than $-20 \mathrm{~dB}$. The impedance bandwidth is $1.71 \%$ ranging from $27.5 \mathrm{GHz}$ to $28.4 \mathrm{GHz}$. The simulated gain of the array at the broadside direction is $18.9 \mathrm{dBi}$ confirming the significant advantage over single element configuration. Figure 6 shows the H-plane and E-plane radiation patterns where half-power beamwidth (HPBW) of $18.3^{\circ}$ across the H-plane is obtained.

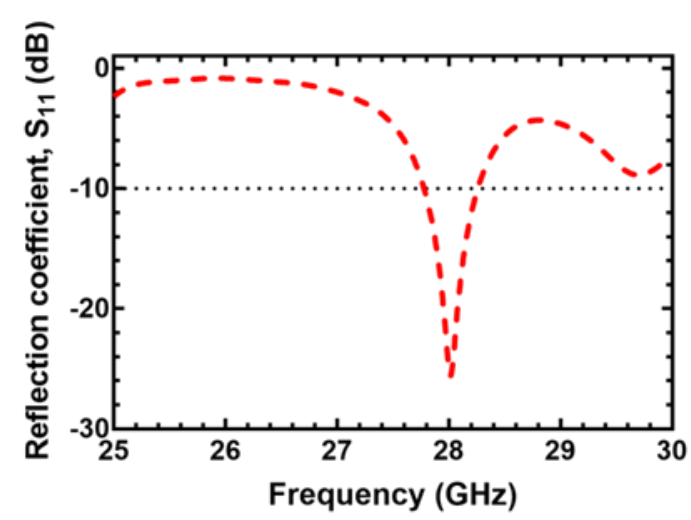

(a)

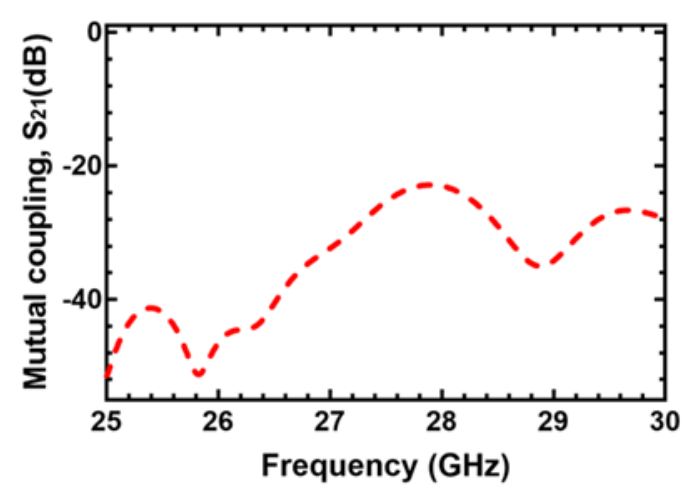

(b)

Figure 5. (a) Simulated reflection coefficient, (b) mutual coupling of the microstrip antenna array in planar configuration

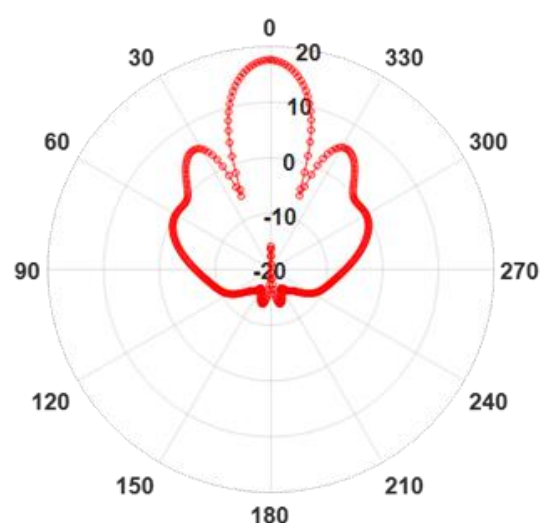

(a)

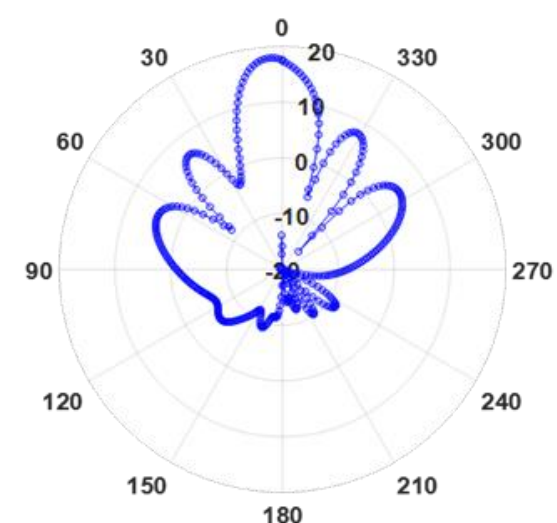

(b)

Figure 6. (a) Simulated H-plane, (b) E-plane radiation pattern of the antenna at $28 \mathrm{GHz}$ for planar configuration

As for the 4-way Wilkinson power divider, the $S_{11}$ for each port is less than $-10 \mathrm{~dB}$ across the operating frequency indicating a properly designed input and output ports as depicted in Figure 7 . The transmission loss, $S_{21}$ between input port, $P_{1}$ and output ports $\left(P_{2}, P_{3}, P_{4}, P_{5}\right)$ are around $6.68 \mathrm{~dB}$ to $7.72 \mathrm{~dB}$ where $1.72 \mathrm{~dB}$ loss ( $-6 \mathrm{~dB}$ for lossless equal split divider) is mainly due to finite conductivity of the metal and dielectric loss of the substrate material. As for the overall structure after integrating the antenna array and the power divider, the $S_{l 1}$ result shows a slight shift in the operating frequency as shown in Figure 8(a). However, the impedance matching at $28 \mathrm{GHz}$ is still intact thus no further optimization is required. As for the gain and the radiation patterns, the results are shown in Figure 8(b) and Figure 9 respectively. In conclusion, the gain and the radiation patterns are similar to that of the array without the power divider. 


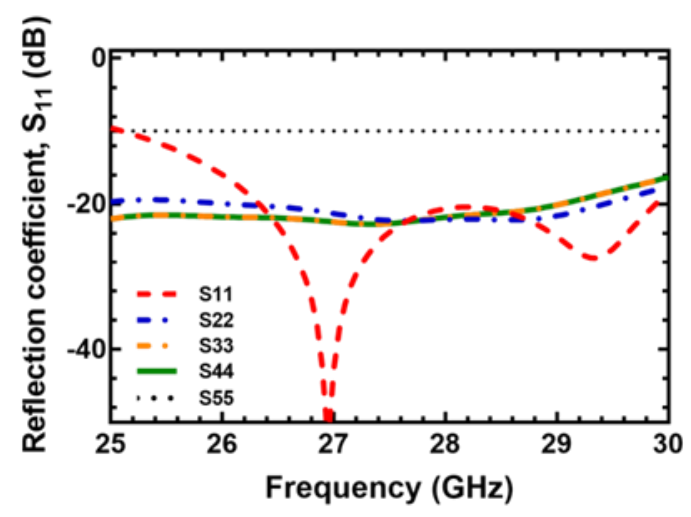

(a)

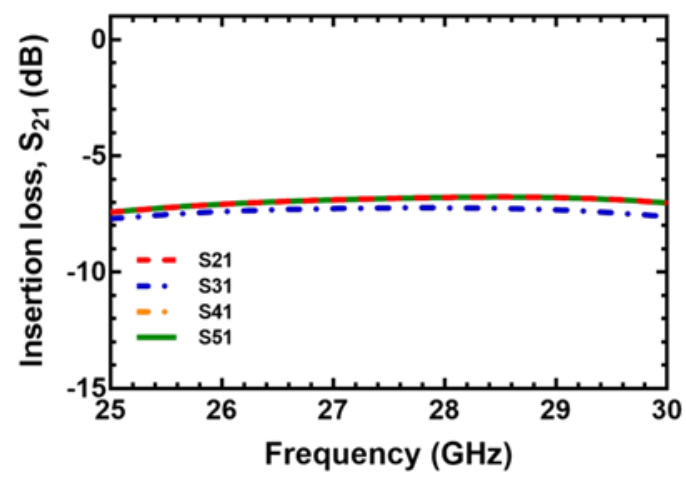

(b)

Figure 7. (a) Simulated reflection coefficient, (b) insertion loss of the 4-way Wilkinson power divider

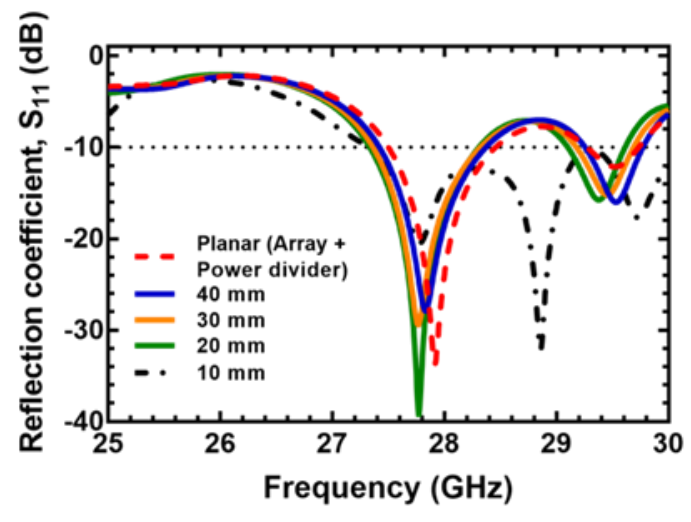

(a)

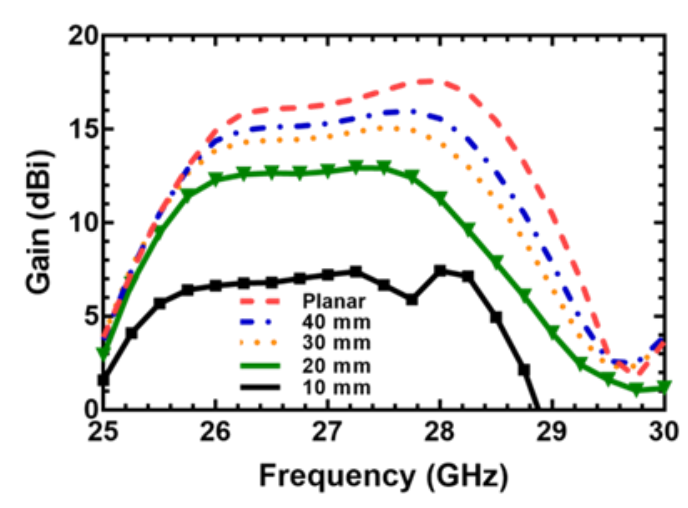

(b)

Figure 8. (a) Simulated reflection coefficients, (b) antenna gains of the devices for various radius of curvatures

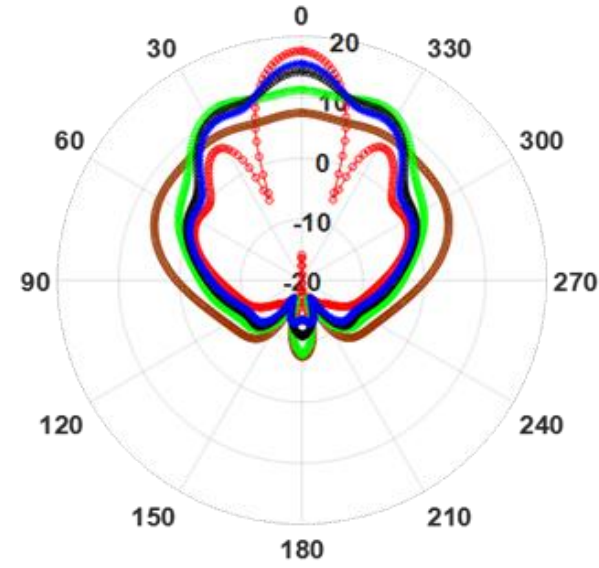

(a)

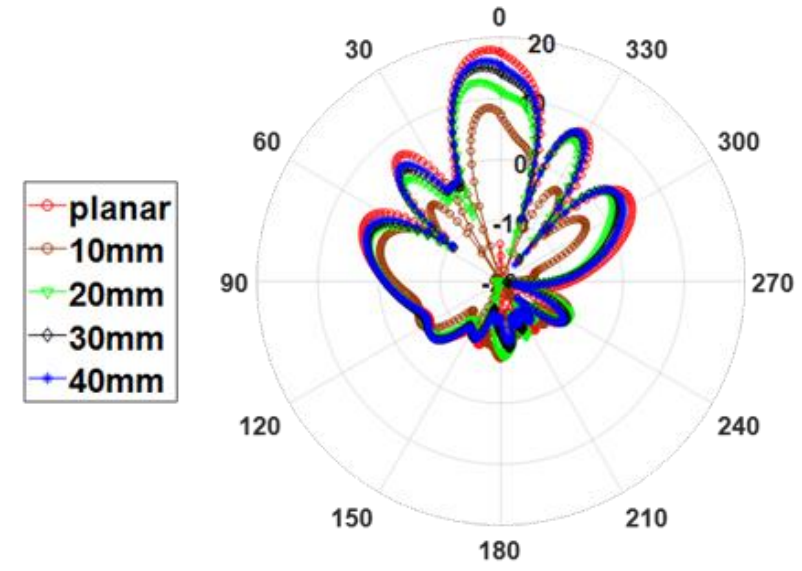

(b)

Figure 9. (a) Simulated H-plane, (b) E-plane radiation pattern of the antenna at $28 \mathrm{GHz}$ for various bending configurations 


\subsection{Effects of bending on antenna performance}

The $S_{11}$ of the antenna for various bending configurations are shown in Figure 8(a). The resonance of the antenna array shifts towards the lower frequency band as the values of the bending radius increase. As for the impedance bandwidth, an increase of the antenna bandwidth can be observed with the increase of the bending radius. Therefore, the bending configuration somehow improves the performance of the antenna. Figure 8(b) and Figure 9 show the maximum gains and radiation patterns for each bending configuration respectively. The gain of the antenna decreases as the bending radius increases. On the other hand, the HPBW of the antenna array increases with the decrease of the bending radius. Antenna with bending radius of $10 \mathrm{~mm}$ demonstrates the lowest gain compared to others with $7.45 \mathrm{dBi}$. Although the antenna has the least gain, its HPBW is the highest with $151.9^{\circ}$ thus better suit for RF energy harvesting applications since RF sources will come from multiple directions instead from one particular direction. It can be concluded that through bending, the HPBW of the antenna can be significantly increased compared to planar form although with reduced gain. Finally, the average simulated specific absorption rate of the antenna is $0.52 \mathrm{~W} / \mathrm{kg}$ which is well below the safety limit of $1.6 \mathrm{~W} / \mathrm{kg}$ averaged over $1 \mathrm{~g}$ of tissue for $100 \mathrm{~mW}$ of input power making it as a feasible solution for wearable energy harvesting system in the future.

\section{CONCLUSION}

In conclusion, we have proposed and demonstrated a wearable milimeter-wave microstrip patch antenna array for RF energy harvesting applications. A $4 \times 4$ antenna array configuration has been utilised and integrated with a 4-way Wilkinson power divider to improve the overall gain of the antenna. The simulated impedance matching performance of the antenna for various bending forms are good with $S_{11}$ values well below $-10 \mathrm{~dB}$ at $28 \mathrm{GHz}$. As for the gain of the antenna, the value decreases from $18.9 \mathrm{dBi}$ to $7.45 \mathrm{dBi}$ as the bending radius decreases from $40 \mathrm{~mm}$ to $10 \mathrm{~mm}$. Meanwhile, HPBW of the antenna improves from $18.3^{\circ}$ to $151.9^{\circ}$ as the bending radius decreases. It is worth noting that for RF energy harvesting purposes, the HPBW is very important design parameter to ensure the antenna can harvest RF sources coming from multiple directions. Therefore, by deforming the antenna array to operate in bending form can actually improve the HPBW significantly. This technique will be applied in future fabrication of the antenna where a foam spacer can be used to support antenna deformation. The antenna is intended to be fabricated using inkjet printing technology.

\section{ACKNOWLEDGEMENTS}

This work was supported by International Islamic University Malaysia (IIUM) under RMC 2020 grant. The authors would like to acknowledge NVIDIA for sponsoring the GPU, Quadro P6000 used in this work through GPU Grant Program.

\section{REFERENCES}

[1] F. Alimenti, V. Palazzi, and P. Mezzanotte, "Smart Hardware for Smart Objects," IEEE Microw. Mag., vol. 19, no. 6 , pp. $48-68,2018$.

[2] J. Kimionis, W. Su, J. Hester, and J. Bito, "Smart Objects," IEEE Microw. Mag., vol. 19, no. 6, pp. 32-47, 2018.

[3] S. Lemey, S. Agneessens, and H. Rogier, "Wearable Smart Objects: Microwaves Propelling Smart Textiles: A Review of Holistic Designs for Wireless Textile Nodes," IEEE Microw. Mag., vol. 19, pp. 83-100, Oct 2018.

[4] S. Salman, Z. Wang, E. Colebeck, A. Kiourti, E. Topsakal, and J. L. Volakis, "Pulmonary edema monitoring sensor with integrated body-area network for remote medical sensing," IEEE Trans. Antennas Propag., vol. 62, no. 5, pp. 2787-2794, 2014.

[5] M. S. R. Bashri, T. Arslan, W. Zhou, and N. Haridas, "Wearable device for microwave head imaging," in 46th European Microwave Conference (EuMC), 2016, pp. 671-674.

[6] G. M. Rebeiz, "5G Millimeter-Wave Radio Technology."

[7] J. G. Andrews et al., "What will 5G be?," IEEE J. Sel. Areas Commun., vol. 32, no. 6, pp. 1065-1082, 2014.

[8] M. H. Alsharif and A. H. Kelechi, "How to make key $5 \mathrm{G}$ wireless technologies environmental friendly: A review," Trans Emerg. Tel Tech, vol. 29, pp. 1-32, 2018.

[9] C. Song, S. Member, Y. Huang, S. Member, and P. Carter, “A Novel Six-Band Dual CP Rectenna Using Improved Impedance Matching Technique for Ambient RF Energy Harvesting," IEEE Trans. Antennas Propag., vol. 64, no. 2, pp. 3160-3171, 2016.

[10] C. Song et al., "A High-Efficiency Broadband Rectenna for Ambient Wireless Energy Harvesting," IEEE Trans. Antennas Propag., vol. 63, no. 8, pp. 3486-3495, 2015.

[11] U. Olgun, C. C. Cheng, and J. L. Volakis, "Design of an efficient ambient WiFi energy harvesting system," IET Microwaves, Antennas Propag., vol. 6, no. 11, pp. 1200-1206, 2012.

[12] H. Sun, Y. Guo, S. Member, M. He, and Z. Zhong, "A Dual-Band Rectenna Using Broadband Yagi Antenna Array 
for Ambient RF Power Harvesting," IEEE Antennas Wirel. Propag. Lett., vol. 12, pp. 918-921, 2013.

[13] J. Bito, S. Member, J. G. Hester, S. Member, and M. M. Tentzeris, "Ambient RF Energy Harvesting From a TwoWay Talk Radio for Flexible Wearable Wireless Sensor Devices Utilizing Inkjet Printing Technologies," IEEE Trans. Microw. Theory Tech., vol. 63, no. 2, pp. 4533-4543, 2015.

[14] T. Lin et al., "On-Body Long-Range Wireless Backscattering Sensing System Using Inkjet- / 3-D-Printed Flexible Ambient RF Energy Harvesters Capable of Simultaneous DC and Harmonics Generation," IEEE Transactions on Microwave Theory and Techniques, vol. 65, no. 12, pp. 5389-5400, 2017.

[15] H. Nishimoto, "Prototype Implementation of Ambient RF Energy Harvesting Wireless Sensor Networks," 2010 IEEE Sensors, pp. 1282-1287, 2010.

[16] M. Arrawatia, M. S. Baghini, and G. Kumar, "RF Energy Harvesting System at 2 . 67 and 5 . 8GHz," 2010 AsiaPacific Microw. Conf., pp. 900-903, 2010.

[17] H. Sun, Y. Guo, S. Member, M. He, and Z. Zhong, "Design of a High-Efficiency 2.45-GHz Rectenna for LowInput-Power Energy Harvesting," IEEE Antennas Wirel. Propag. Lett., vol. 11, pp. 929-932, 2012.

[18] S. Keyrouz, H. J. Visser, and A. G. Tijhuis, "Multi-band Simultaneous Radio Frequency Energy Harvesting," 2013 7th Eur. Conf. Antennas Propag., no. Eucap, pp. 3058-3061, 2013.

[19] T. M. Chiam, L. C. Ong, M. F. Karim, and Y. X. Guo, "5 . 8GHz Circularly Polarized Rectennas Using Schottky Diode and LTC5535 Rectifier for RF Energy Harvesting," 2009 Asia Pacific Microw. Conf., pp. 32-35, 2009.

[20] A. Georgiadis, S. Member, G. Andia, and A. Collado, "Rectenna Design and Optimization Using Reciprocity Theory and Harmonic Balance Analysis for Electromagnetic ( EM ) Energy Harvesting," IEEE Antennas Wirel. Propag. Lett., vol. 9, pp. 444-446, 2010.

[21] M. Arrawatia, "RF Energy Harvesting System from Cell Towers in 900MHz Band," 2011 Natl. Conf. Commun., pp. 1-5, 2011.

[22] P. In, "Design of RF Energy Harvesting System For Energizing Low Power Devices," Prog. Electromagn. Res., vol. 132, pp. 49-69, 2012.

[23] R. K. Pokharel and K. Yoshida, "Energy Harvesting Circuit on a One-Sided Directional Flexible Antenna," IEEE Microw. Wirel. Components Lett., vol. 23, no. 3, pp. 164-166, 2013.

[24] F. Xie, G. Yang, and W. Geyi, "Optimal Design of an Antenna Array for Energy Harvesting," IEEE Antennas Wirel. Propag. Lett., vol. 12, pp. 155-158, 2013.

[25] K. Agarwal et al., "Highly Efficient Wireless Energy Harvesting System using Metamaterial based Compact CP Antenna," 2013 IEEE MTT-S Int. Microw. Symp. Dig., pp. 1-4, 2013.

[26] W. Haboubi, H. Takhedmit, J. L. S. Luk, S. Adami, and B. Allard, "An Efficient Dual-Circularly Polarized Rectenna for RF Energy Harvesting in the 2.45 GHz ISM Band,” Prog. Electromagn. Res., vol. 148, pp. 31-39, 2014.

[27] M. Arrawatia, M. S. Baghini, S. Member, and G. Kumar, "Differential Microstrip Antenna for RF Energy Harvesting," IEEE Trans. Antennas Propag., vol. 63, no. 2, pp. 1581-1588, 2015.

[28] A. Mavaddat, S. Hossein, M. Armaki, and A. R. Erfanian, "Millimeter-Wave Energy Harvesting Using 4 x 4 Microstrip Patch Antenna Array," IEEE Antennas Propag. Lettters, vol. 14, pp. 515-518, 2015.

[29] Q. Awais, Y. Jin, H. T. Chattha, S. Member, and B. A. Khawaja, "A Compact Rectenna System With High Conversion Efficiency for Wireless Energy Harvesting," IEEE Access, vol. 6, pp. 35857-35866, 2018.

[30] V. Palazzi et al., "A Novel Ultra-Lightweight Multiband Rectenna on Paper for RF Energy Harvesting in the Next Generation LTE Bands," IEEE Trans. Microw. Theory Tech., vol. 66, no. 1, pp. 366-379, 2018.

[31] A. Takacs, A. Okba, and H. Aubert, "Compact Planar Integrated Rectenna for Batteryless IoT Applications," 2018 48th Eur. Microw. Conf., pp. 777-780, 2018.

[32] Y. Hu, S. Member, S. Sun, and S. Member, "Grid-Array Rectenna With Wide Angle Coverage for Effectively Harvesting RF Energy of Low Power Density," IEEE Trans. Microw. Theory Tech., vol. 67, no. 1, pp. 402-413, 2019.

[33] "GSMA $26 \mathrm{GHz}$ and $28 \mathrm{GHz}$ are both needed for 5G - Spectrum." [Online]. Available: https://www.gsma.com/spectrum/resources/26-ghz-28-ghz/. [Accessed: 07-Aug-2019].

[34] C. A. Balanis, Antenna Theory: Analysis and Design. 2012.

[35] M. Haghzadeh, C. Armiento, and A. Akyurtlu, "Microwave Dielectric Characterization of Flexible Plastic Films Using Printed Electronics," 2016 87th ARFTG Microwave Measurement Conference (ARFTG), San Francisco, CA 2016, pp. 1-4.

[36] D. M. Pozar, Microwave Engineering. Wiley, 2005.

[37] H. Zou, H. Zhang, C. Song, H. Wang, and P. Wang, "Characterisation and modelling of mitered coplanar waveguide bends on silicon substrate,” Int. J. Electron., vol. 97, no. 6, pp. 715-727, 2010. 


\section{BIOGRAPHIES OF AUTHORS}

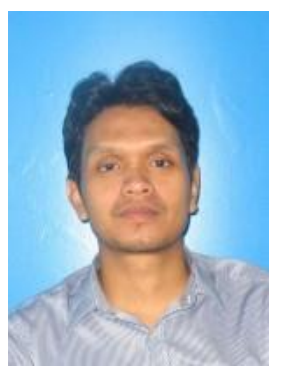

Mohd Saiful Riza Bashri received the Bachelor degree in communication engineering and Master of Science in electronics engineering from International Islamic University Malaysia (IIUM) in 2009 and 2014 respectively. He obtained his Ph.D. degree in engineering from The University of Edinburgh, Scotland in 2018. Currently, he is an assistant professor with the Department of Science in Engineering, Kulliyyah of Engineering, IIUM. His research interests include antenna design, microwave based biomedical imaging, RFID and biosensors.

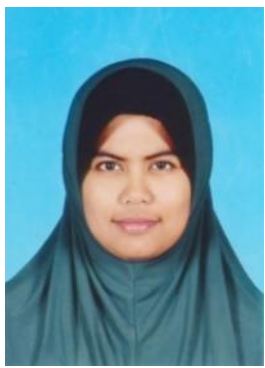

Noor Amalina Ramli received the Bachelor degree in communication engineering and Master of Science in electronics engineering from International Islamic University Malaysia (IIUM) in 2009 and 2013 respectively. She obtained her Ph.D. degree in engineering from The University of Edinburgh, Scotland in 2019. She is currently doing her postdoctoral study at IIUM. Her research interests include MEMS design, phase shifters and strain sensors. 